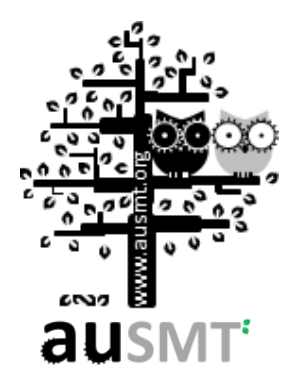

\title{
Establishing Urban Industrial Parks to Drive Regional Innovation System
}

\section{Chih-Lun Chen*}

Market Intelligence \& Consulting Institute (MIC), Institute for Information Industry (III), Taiwan

(Received 25 November 2012; Published on line 1 December 2012)

*Corresponding author: chihlun@micmail.iii.org.tw

DOI: 10.5875 /ausmt.v2i4.181

O ver the past five decades, more than 150 industrial parks have been established in Taiwan by the central government, local governments and the private sector. There has often been intense competition between individual industrial parks, because of unclear positioning or lack of clarity in the park's development strategy. This rivalry has had a negative impact on the level of synergy that industrial parks have been able to create, and has also had a negative influence on the formation of strong industry clusters. In the past, the formulation of industrial development strategy and the making available of land for industry were the responsibilities of different government agencies; the resulting lack of coordinated planning has become a major obstacle that hinders successful industry cluster development and the transformation of Taiwanese industry into achieving high value-added production. Besides allocating more funding to ensure coordinated planning of land use and industrial development, the government also needs to rethink the positioning of Taiwan's industry clusters and ensure that the platforms and incentives needed to support innovation are in place. The government should be seeking to help business enterprises adopt automation technology and integrated energy source utilization, while promoting the development of specialized industry clusters and encouraging individual regions within Taiwan to build industries with a distinctive regional character.

\section{More attention needs to be paid to the key issues relating to local development and industrial innovation}

In light of the needs of regional spatial development and sustainable industrial development, there are several key social, economic and environmental issues that need to be addressed.

Over the past few years, population issues have gradually emerged as a major focus of attention in Taiwan. According to statistics compiled by the Council for Economic Planning and Development (CEPD), as of December 2010, 79.4\% of Taiwan's citizens approximately 18.3 million people - were living in urban areas; this represents a level of urbanization on a par with the advanced nations of Europe and North America. With urban planning zones accounting for only $12.7 \%$ of Taiwan's total land area, the population density within urban areas is very high, making it all the more important that cities function properly and that sufficient employment opportunities are available. A further problem that Taiwan must face is the trend towards smaller families and the aging of the population. Analysis conducted by the Market Intelligence \& Consulting Institute (MIC), Institute for Information Industry indicates that, given the current percentage of people remaining single throughout their lives and the current birth rate, around $30 \%$ of women born in Taiwan in 1990 will have no children, and $40 \%$ will have no grandchildren 
(in Taiwan, this is known as the "9034" phenomenon). As of December 2010, there were just over 2.48 million people in Taiwan aged 65 or over, accounting for approximately $10.7 \%$ of the population. By 2020 , this figure will have risen to 3.68 million, representing an increase of around 1.2 million in just ten years; one person in every 6.36 will be a senior citizen. Over the same period, the number of young people in Taiwan will fall from 5.23 million in 2010 to just under 3.98 million in 2020, a decline of around 1.2 million. This dramatic shift in the population structure is likely to have a severe negative impact on Taiwan's R\&D capabilities and on the vitality of individual regions within Taiwan. If Taiwan is to maintain its competitiveness, it needs to focus on making industrial development more efficient, and on enhancing the level of automation.

Taiwan is currently also faced with some severe challenges in terms of its industrial development. During the early stages of Taiwan's economic development, the establishment of industrial parks and industrial districts was undertaken in a rather unsystematic manner, and there was a lack of clear guidance with regard to industrial positioning. As a result, although industry clusters did take shape in some industrial parks, as far as the establishment of regional innovation systems is concerned, Taiwan failed to develop strategies for the positioning and coordination of industry clusters in key industries. At the same time, the steady expansion in Taiwan's urban population and in the area covered by its urban areas meant that some older industrial parks which had originally been located on the fringes of urban areas found that they were now situated well inside urban areas, within the areas in which urban residents undertake their daily living activities. In addition, since the 1980s Taiwan has experienced two waves of industrial production being relocated overseas. As a result, many areas that were formerly dedicated to industrial production have been left vacant or idle. The extent to which the government can undertake effective investment to improve the image of the affected regions, providing guidance for the formation of new, high-efficiency industry clusters and promoting a transformation and upgrading of the industrial structure, will be a key factor in determining whether Taiwanese industry can reorient itself towards flexible, high value-added production, thereby contributing to the economic growth and prosperity of the nation as a whole.

As far as the macroeconomic environment is concerned, in its international competitiveness rankings the World Economic Forum (WEF) has for several years in a row rated Taiwan as number one in the world for industry cluster development. Nevertheless, there are many manufacturers in Taiwan that are forced to transport unfinished products from one part of Taiwan to another during the production process. Besides increasing the burden on the environment, this situation is also inefficient in terms of time and costs. Then there is the question of recent international trends in energy conservation and carbon reduction. Both the capital markets and consumers are paying more and more attention to corporate disclosure with respect to ESG (Environmental, Social and Governance) issues and the strategies that business enterprises are adopting in response to climate change. In the future, the "green governance" of both individual firms and the industrial parks where they are located will constitute fundamental criteria for business appraisal, investment decisions and the selection of contract manufacturing partners. With other countries enhancing their capabilities in terms of manufacturing automation and flexible, precision manufacturing, while at the same time the trend towards imposition of ever stricter environmental standards is becoming more pronounced, the pressures on manufacturing firms are no longer limited to pressure to reduce costs. The key challenges for both individual firms and entire industries today include keeping pace with changes in international regulations and the need to develop "green" high value added manufacturing.

\section{Building regional innovation systems that reflect regional characteristics while still being competitive}

Given the existence of the issues outlined above, as well as the dawning of the era of the "innovation economy," technology innovation has become one of the most important aspects of industrial development, and a key factor influencing economic growth. Countries throughout the world have been working actively to develop their innovation systems, and to promote the creation, diffusion and application of knowledge within the system. As the composition (and specialist capabilities) of the participants in innovation systems varies from region to region, there is also variation in the extent and effectiveness of innovation activity; at the same time, the form taken by existing industry clusters also varies between localities. What this means in practice is that promoting innovation at the local level and stimulating regional economic development is no longer just a task for local government authorities; increasingly, central government agencies are coming to recognize the importance of this work.

The biggest difference between regional innovation and national-scale innovation lies in the fact that individual regional innovation systems have their 
own unique individual characteristics. Emphasis thus needs to be placed on the question of how to promote the flow of knowledge and resources between the various different actors that make up the regional innovation system, including government agencies, business enterprises, universities, research institutes, intermediary organizations, investors, etc., and how collaboration and competition can be used to effectively stimulate innovation activity within the region, thereby helping to enhance regional competitiveness and achieving regional economic growth objectives. It is even more important to recognize that every member of an innovation system has their own particular functions and responsibilities. Government is responsible for providing universities, research institutes and business enterprises with a first-class environment for science and technology innovation, while at the same time also working to build sound capital markets that can help enterprises to develop. The role entrusted to academic and research institutions is that of meeting the technological needs of regional industries and contributing to manpower cultivation. As regards the industries located within a given region, they have a key role to play in terms of commercializing knowledge and technology and bringing products to the market; their activities are often the single biggest factor determining whether a given innovation system is successful. To put it another way, in order to be able to build up a first-class innovation system, you need to be able to influence first-class business enterprises to locate themselves in the area, and make it possible for them to make effective use of local R\&D capabilities. Doing so will benefit the enterprises concerned, but will also stimulate the development of the entire region, and will contribute to the ongoing development of other innovation system members (for example, by ensuring that the outstanding human talent cultivated by local universities have jobs to go to after graduation, etc.), thereby helping to create a "virtuous circle."

In light of the above, it can be seen that the competitive advantage held by individual clusters and the mechanisms used to identify aspects of innovation with significant potential for future development have an important role to play in improving regional innovation system planning and developing local specialization. Most of the research that has been done to date on regional advantage has made use of the location quotient method, which is useful for measuring the importance of a given industry within a particular region as compared to its importance within the nation as a whole. However, in Taiwan the only real source of nationwide, industry-specific data is the Industry, Commerce and Service (ICS) Census, which is conducted once every five years. As this data tends to become out of date very quickly, there is a danger that identification of industries that possess regional advantage may become out of sync with industrial development planning for the future. In order to minimize the impact of the time lag with respect to Census data, MIC has developed the I'PS (Industry \& Innovation Positioning System) research method, to assist in the identification of industries that possess regional advantage.

While the ICS Census can give a picture of current or past industrial development status, efforts to evaluate which industries have significant future development potential requires new ways of thinking that focus on those industries with strong potential for innovation, and for the development of new products and new markets. The I'PS method takes existing location quotients as its baseline, and uses employment and production value to identify a given region's existing "main industries." The $I^{2} P S$ method also adopts the concept of the "human talent quotient," to explore the cultivation and availability of human talent at the regional level, to help identify "industries with potential" that have significant potential for future development. The results obtained for main industries and industries with potential are then combined to identify the "regional advantage industries" to which industrial development in the region in question is most suited. Besides implementing industry-specific evaluation of the availability of human talent, employment intensity and production value, the $\mathrm{I}^{2} \mathrm{PS}$ method also involves a "stock-taking" of the level of research (measured in terms of academic papers published) and development (measured in terms of patents) for a given region. The results obtained are synthesized with the regional advantage industry appraisal results, to assist the government in identifying regional advantage industries and industries that have the potential to drive future growth, and to facilitate the formulation of planning for industrial development, manpower cultivation, public construction and allocation of $R \& D$ resources.

\section{Urban industrial parks can serve as the "engine" for driving regional innovation}

When seeking to build up a regional innovation system, industrial parks constitute a useful test-bed that is able to combine efficient operation with the opportunity to tailor solutions to local conditions. For governments, industrial parks can be seen as functioning as a vehicle for social, political and economic policy, and as a tool for the realization of policy objectives. The value of industrial parks lies in their special systemic arrangements. While the government needs to provide 
"logistical support" in the form of suitable land, water, electricity and gas supply, air and water pollution treatment facilities, telecommunications links, highways, factory buildings, warehousing facilities etc., as well as employee dormitories and facilities for special gases, special water usage needs, special materials, etc., to help firms that locate themselves in an industrial park get off the ground, the government also benefits in the form of increased tax revenue. For the companies involved in developing industrial parks, an industrial park is a unique form of development project. Through the planning of industrial parks, developers can help the government to realize its development objectives, while they themselves obtain revenue from the leasing or sale of land. For universities and colleges, industrial parks can serve as a test-bed for R\&D work and as a target for technology transfer. For business enterprises, industrial parks represent a platform through which they can access low-cost production factors and regional assets (including policy incentives, infrastructure, distribution channels, etc.).

Given that $79.4 \%$ of Taiwan's population is living in urban areas, and bearing in mind the key environmental, social and economic trends that are affecting Taiwan today, the creation of innovation eco-systems (with a focus on high-value, highly automated innovation activities) in urban areas with high population density (such as Taipei City's Nangang Software Park, the Hsinchuang District of New Taipei City, and other key industrial development zones in Taiwan's five major metropolitan areas) can help to drive growth at the regional level, optimize the industrial structure and provide strengthened support for sustainable development. Given this premise, the establishment of "urban industrial parks" that would integrate government policy input with manpower and talent cultivation, land use and industrial development planning, and venture capital and start-up resources, is a strategy that warrants serious consideration.

With the increased emphasis on transforming industry towards high value added production and the rise in environmental consciousness among the nation's citizens, urban residents in Taiwan today do not have to worry about having high-polluting, high energy consumption heavy industry in the vicinity of their homes. At the same time, the firms located in industrial parks that are situated inside or on the periphery of urban areas, as well as small and medium enterprises (SMEs) and enterprises belonging to traditional industries that located in urban areas, are in need of innovation capabilities to support their continued development in the next generation. Urban industrial parks that possess innovation and creativity, and that are "green," with low energy consumption and a high level of automation, can play a leading role in the development of regional innovation systems. The places where this new type of industrial park will be located are all important economic hubs - they are centers for logistics management, knowledge creation, information convergence and technology innovation. These locations have the additional advantage of proximity to important markets and ready access to financing and marketing functions. Furthermore, there is an extensive pool of human resources available to support industrial park operation. The employment opportunities, scope for industry-university collaboration, R\&D test-bed functionality and support for technology innovation and upgrading that urban industrial parks provide can help to create a virtuous circle with respect to the transformation of the regional industrial structure and boosting carrying capacity. At the same time, the more extensive the money flow, information flow and innovation capability that a given city can attract, identify and process, the more influence that city can exert within the global network of major cities.

Urban industrial park design initiatives and pilot projects are mushrooming in Taiwan's major metropolitan areas, including New Taipei City. The goal is to build practicable, replicable, extensible planning systems and operational mechanisms, so that regional innovation can grow and spread, helping to drive sustainable development for both individual regions and the country as a whole. 